\title{
Association of an $A P O C 3$ promoter variant with type 2 diabetes risk and need for insulin treatment in lean persons
}

\author{
M. van Hoek • T. W. van Herpt • A. Dehghan • \\ A. Hofman • A. G. Lieverse - C. M. van Duijn • \\ J. C. M. Witteman • E. J. G. Sijbrands
}

Received: 1 November 2010 / Accepted: 25 January 2011 / Published online: 4 March 2011

(C) The Author(s) 2011. This article is published with open access at Springerlink.com

\begin{abstract}
Aims/hypothesis An APOC3 promoter haplotype has been previously associated with type 1 diabetes. In this population-based study, we investigated whether $A P O C 3$ polymorphisms increase type 2 diabetes risk and need for insulin treatment in lean participants.

Methods In the Rotterdam Study, a population-based prospective cohort $(n=7,983)$, Cox and logistic regression models were used to analyse the associations and interactive effects of $A P O C 3$ promoter variants $(-482 \mathrm{C}>\mathrm{T}$, $-455 \mathrm{~T}>\mathrm{C})$ and $\mathrm{BMI}$ on type 2 diabetes risk and insulin treatment. Analyses were followed by replication in an independent case-control sample (1,817 cases, 2,292 controls) and meta-analysis.

Results In lean participants, the $-482 \mathrm{~T}$ allele was associated with increased risk of prevalent and incident type 2 diabetes: OR $-482 \mathrm{CT} 1.47$ (95\% CI 1.13-1.92), -482TT 1.40 (95\% CI 0.83-2.35), $p=0.009$ for trend; HR $-482 \mathrm{CT}$
\end{abstract}

M. van Hoek · T. W. van Herpt • E. J. G. Sijbrands $(\bowtie)$ Department of Internal Medicine, Erasmus Medical Center, PO Box 2040, 3000 CA, Rotterdam, the Netherlands

e-mail: e.sijbrands@erasmusmc.nl

M. van Hoek • A. Dehghan - A. Hofman • C. M. van Duijn •

J. C. M. Witteman

Department of Epidemiology and Biostatistics,

Erasmus University Medical Center,

Rotterdam, the Netherlands

T. W. van Herpt - A. G. Lieverse

Department of Internal Medicine, Maxima Medical Center,

Eindhoven, the Netherlands

C. M. van Duijn

Department of Clinical Genetics, Genetic Epidemiology Unit, Erasmus University Medical Center,

Rotterdam, the Netherlands
1.35 (95\% CI 0.96-1.89), -482TT 1.68 (95\% CI 0.91-3.1), $p=0.03$ for trend, respectively. These results were confirmed by replication. Meta-analysis was highly significant $\left(-482 \mathrm{~T}\right.$ meta-analysis $\left.p=1.1 \times 10^{-4}\right)$. A borderline significant interaction was observed for insulin use among participants with type 2 diabetes $(-482 \mathrm{CT} * \mathrm{BMI} p=0.06$, $-455 \mathrm{TC} * \mathrm{BMI} p=0.02$ ).

Conclusions/interpretation At a population-based level, the influence of $A P O C 3$ promoter variants on type 2 diabetes risk varies with the level of adiposity. Lean carriers of the $-482 \mathrm{~T}$ allele had increased type 2 diabetes risk, while such an effect was not observed in overweight participants. Conversely, in overweight participants the $-455 \mathrm{C}$ allele seemed protective against type 2 diabetes. The interaction of the variants with need for insulin treatment may indicate beta cell involvement in lean participants. Our findings suggest overlap in the genetic backgrounds of type 1 diabetes and type 2 diabetes in lean patients.

Keywords $A P O C 3 \cdot \mathrm{BMI} \cdot$ Polymorphism · Type 1 diabetes Type 2 diabetes

\begin{tabular}{ll}
\multicolumn{2}{l}{ Abbreviations } \\
ApoC-III & Apolipoprotein C-III \\
IRE & Insulin/phorbol ester responsive element \\
LPL & Lipoprotein lipase \\
RS1 & Rotterdam study \\
RSPlus1 & Rotterdam study plus 1
\end{tabular}

\section{Introduction}

Type 2 diabetes mellitus is characterised by overweight, impaired insulin secretion and insulin resistance [1]. Nevertheless, a substantial proportion of patients with type 2 
diabetes are lean $[2,3]$. These patients would seem to suffer predominantly from impaired insulin secretion [4-6], whereas obese patients would be more resistant to insulin [7]. Defective insulin secretion has higher heritability estimates than insulin resistance in family and twin studies [8-10], and the concordance rate for type 2 diabetes in lean twins is higher than that in obese twins [11]. This suggests higher genetic susceptibility in lean type 2 diabetes and involvement of pancreatic beta cell dysfunction.

Lean type 2 diabetes has a number of similarities to type 1 diabetes. Interestingly, type 1 diabetes is more frequent in families with type 2 diabetes and vice versa [12, 13], a fact that supports the hypothesis of genetic overlap between the two diseases. In a paper by Hokanson et al., an APOC3 haplotype determined by two promoter polymorphisms $(-455 \mathrm{~T}>\mathrm{C}$ and $-482 \mathrm{C}>\mathrm{T})$ was associated with type 1 diabetes [14]. Apolipoprotein C-III (ApoC-III) is an apolipoprotein involved in triacylglycerol metabolism. It inhibits lipoprotein lipase (LPL) and mediates lipoprotein uptake by the liver [15]. Higher ApoC-III production raises triacylglycerol and NEFA levels, and thus may affect beta cell function. $[16,17]$ On the other hand, ApoC-III has been suggested to directly bring on beta cell death [18]. Located in an insulin/phorbol ester responsive element (IRE), the promoter polymorphisms curb the capacity of insulin to downregulate the gene $[19,20]$. In view of this evidence, we hypothesised that polymorphisms in the APOC3 gene increase susceptibility of lean individuals to type 2 diabetes and that lean carriers of these polymorphisms with type 2 diabetes are more susceptible to insulin deficiency.

In the present population-based study, we investigated whether the $A P O C 3-482 \mathrm{C}>\mathrm{T}$ and $-455 \mathrm{~T}>\mathrm{C}$ polymorphisms influence type 2 diabetes risk in lean persons. This was followed by replication testing in an independent sample. In addition, we investigated the associations with need for insulin treatment among type 2 diabetes participants from the Rotterdam Study (RS1).

\section{Methods}

Study population Details of the RS1 have been described elsewhere [21]. In brief, the RS1 was a prospective, population-based cohort study investigating determinants of chronic diseases in the elderly. A total of 7,983 inhabitants of a Rotterdam suburb, aged 55 years or older, were included. Baseline examinations were performed with follow-up measurements at 1-3 year intervals. Linkage to general practitioners' records provided continuous monitoring of major disease outcomes. Municipal health authorities regularly provided information on vital status.

In accordance with the guidelines of the ADA [21, 22] and WHO [23], diabetes was defined as a fasting plasma glucose level $\geq 7.0 \mathrm{mmol} / \mathrm{l}$ and/or a non-fasting plasma glucose level $\geq 11.0 \mathrm{mmol} / 1$ and/or treatment with oral glucose-lowering medication or insulin, and diagnosis of diabetes as registered by a general practitioner. Prevalent cases of diabetes were diagnosed at baseline by a non-fasting or post-load glucose level (after OGTT) $\geq 11.1 \mathrm{mmol} / \mathrm{l}$ and/or treatment with oral glucose-lowering medication or insulin, and by diagnosis of diabetes as registered by a general practitioner.

For the present study, general practitioners' records were searched for type 1 diabetes diagnoses and these participants were excluded. Data on insulin treatment were derived from interviews at baseline and the pharmacy database, which provided prospective data on prescribed insulin.

Written informed consent was obtained from all participants and the Medical Ethics Committee of the Erasmus Medical Center approved the study. For the present study, baseline data were collected between 1990 and 1993. Follow-up data were available until 1 October 2005.

Replication cohort The Rotterdam Study Plus 1 (RSPlus1) (290 cases, 2,292 controls) and the DiaGene study (1,527 cases) were used as a combined replication cohort (RSPlus1/DiaGene). RSPlus1 is an additional part of the prospective population-based RS1 and has been described in detail elsewhere [21]. The DiaGene study is an ongoing collection of type 2 diabetes cases and controls from the city of Eindhoven, the Netherlands. At the time of this replication effort, 1,527 DiaGene cases were available for genotyping. RSPlus1 and DiaGene cases were diagnosed according to the guidelines of the WHO [23] and ADA $[21,22]$, and/or based on treatment with oral glucoselowering medication or insulin. RSPlus1 and DiaGene cases did not significantly differ in terms of age, sex and BMI, and were combined in the analyses.

Written informed consent was obtained from all participants and the Medical Ethics Committee of the Erasmus Medical Center approved the study.

Genotyping In the $A P O C 3$ gene, the $-482 \mathrm{C}>\mathrm{T}(\mathrm{rs} 2854117)$ and $-455 \mathrm{~T}>\mathrm{C}$ (rs2854116) promoter polymorphisms were chosen for genotyping on the basis of the ability to tag the variation previously associated with type 1 diabetes, and earlier associations with measures of glucose metabolism and localisation in an IRE [14, 24-26].

Genotyping was performed with TaqMan allelic discrimination assays designed and optimised by Applied Biosystems (Foster City, CA, USA). Reactions were performed on the TaqMan Prism 7900HT platform. The duplicates mismatch rate was 0.003 and 0.02 in the RS1 and 0.018 and 0.044 in the RSPlus1/DiaGene cohorts for the $-482 \mathrm{C}>\mathrm{T}$ and $-455 \mathrm{~T}>\mathrm{C}$ polymorphisms, respectively. Genotype success rates for $-482 \mathrm{C}>\mathrm{T}$ and $-455 \mathrm{~T}>\mathrm{C}$ were 
0.95 and 0.94, and 0.96 and 0.97 in the RS1 and RSPlus1/

DiaGene cohorts respectively.

Laboratory analyses In 3,930 participants fasting plasma samples were available at the second follow-up visit of the study for measurement of triacylglycerol. Triacylglycerol levels were measured by enzymatic colorimetric methods (CHOD-PAP and GPO-PAP; Boehringer Mannheim, Mannheim, Germany) on an analyser (Hitachi 911; Boehringer Mannheim).

Statistical methods Analyses were performed with SPSS software version 16.0 (SPSS, Chicago, IL, USA). Linkage disequilibrium was calculated with GOLD version 1.0. (http://www.sph.umich.edu/csg/abecasis/GOLD/, accessed 1 January 2007). Continuous variables are expressed as means $\pm \mathrm{SD}$. Comparisons between groups were performed with independent samples $t$ tests and $\chi^{2}$ tests for normally distributed continuous and categorical variables, respectively. Triacylglycerol levels were not normally distributed and therefore logarithmically transformed before the analyses. ANOVA was used for comparison of continuous variables between more than two groups. Deviations from HardyWeinberg equilibrium were assessed by means of $\chi^{2}$ testing. Genotype frequencies were compared between incident and prevalent cases, and participants without type 2 diabetes.

In RS1, we tested the associations of the genotypes with type 2 diabetes and their interactions with BMI in logistic regression models and prospectively in Cox proportional hazards models for prevalent and incident type 2 diabetes, respectively. Participants with prevalent type 2 diabetes at baseline were excluded from the prospective analyses.

In the RSPlus1/DiaGene cohort we repeated the analyses described above using logistic regression. Haplotype analyses did not add any further information on analyses of the individual genotypes and are therefore not shown here.

To test the hypothesis of beta cell involvement, we tested the associations of genotypes with insulin treatment and their interactions with BMI in a logistic regression model in RS1 in patients with type 2 diabetes. Prevalent and incident insulin use was included in these analyses. Linear regression models were used to analyse the association between the polymorphisms and fasting triacylglycerol levels. All models were adjusted for year of birth and sex.

All analyses described above were repeated in two subgroups stratified for BMI using the RS1 population median. Lean persons had a BMI equal to or below $26 \mathrm{~kg} / \mathrm{m}^{2}$ and overweight persons had a BMI above $26 \mathrm{~kg} / \mathrm{m}^{2}$.

The $p$ values found in RS1 and RSPlus1/DiaGene were combined by a $Z$-based meta-analysis using beta, standard error and number of participants of each cohort.
Combining RS1 and RSPlus1/DiaGene, we had 98\% power to detect an effect of OR 1.3 (minor allele frequency $0.20)$ in the lean group $(n=802$ cases, i.e. the smallest group of cases analysed for type 2 diabetes).

\section{Results}

Baseline characteristics RS1 Diabetes status was available for 6,362 successfully genotyped persons. Participants whose genotyping was not successful or whose DNA was not available were 5.8 years older and included $8.5 \%$ more women. Nevertheless, the genotyped and not genotyped groups had similar distributions of BMI, waist circumference and presence of type 2 diabetes.

Participants with type 2 diabetes (prevalent and incident) had significantly higher BMI and waist circumference, and lower HDL-cholesterol, than those without type 2 diabetes (Table 1). Prevalent cases were significantly older and had significantly lower BMI than incident cases.

Population genetics In the total population and BMI subgroups, the polymorphisms were in Hardy-Weinberg equilibrium $\left(\chi^{2}<3.35, d f 1, p>0.07\right)$. Heterozygosity for the $-482 \mathrm{~T}$ allele was found in $34.6 \%$ of participants; $5.9 \%$ were homozygous. For the $-455 \mathrm{C}$ allele these percentages were $43.0 \%$ and $12.6 \%$, respectively. There was a strong linkage disequilibrium between the two polymorphisms, $D^{\prime}=0.968 \quad(p<0.000001), r^{2}=0.54$. Frequencies of genotypes did not differ significantly between participants with and without type 2 diabetes, or between incident and prevalent cases in the total population (data not shown).

We identified four haplotypes, $\mathrm{H} 1$ to $\mathrm{H} 4$, according to decreasing population frequency. $\mathrm{H} 1 \mathrm{was}$ defined by the absence of both minor alleles, $\mathrm{H} 2$ by the presence of both minor alleles, $\mathrm{H} 3$ by only the presence of the -455 minor allele and $\mathrm{H} 4$ by the presence of the -482 minor allele. The allele frequencies of $\mathrm{H} 1, \mathrm{H} 2$ and $\mathrm{H} 3$ were $64.4 \%, 23.4 \%$ and $11.8 \%$, respectively.

Type 2 diabetes risk in lean and overweight persons In the total population, none of the genotypes significantly influenced the risk of type 2 diabetes. Adjustment for BMI and waist circumference did not change these results (data not shown).

We observed an effect of the interaction of $-482 \mathrm{C}>\mathrm{T}$ and $-455 \mathrm{~T}>\mathrm{C}$ polymorphisms with $\mathrm{BMI}$ on prevalent type 2 diabetes $(-482 \mathrm{C}>\mathrm{T} * \mathrm{BMI}, p=0.01 ;-455 \mathrm{~T}>\mathrm{C} * \mathrm{BMI}$ $p=0.01)$. Similar findings were observed prospectively for effect on the risk of incident type 2 diabetes $(-482 \mathrm{C}>$ $\mathrm{T} * \mathrm{BMI}, p=0.002 ;-455 \mathrm{~T}>\mathrm{C} * \mathrm{BMI}, p=0.03$ ).

Table 2 shows ORs for prevalent type 2 diabetes and HRs for incident type 2 diabetes according to APOC 3 promoter genotype in lean and overweight persons. In lean 
Table 1 RS1 baseline characteristics of all participants and patients with and without type 2 diabetes

\begin{tabular}{|c|c|c|c|c|c|}
\hline Characteristics & All participants & Without diabetes & Prevalent cases & Incident cases & $p$ value \\
\hline$N$ & 6,362 & 5,156 & 661 & 545 & \\
\hline Age (years) & $69.4 \pm 9.1$ & $69 \pm 9.1$ & $73.5 \pm 9.2$ & $68.4 \pm 7.9$ & $<0.001^{\mathrm{a}, \mathrm{b}}$ \\
\hline Men $(\%)$ & 40.6 & 40.4 & 39.5 & 44 & NS \\
\hline BMI $\left(\mathrm{kg} / \mathrm{m}^{2}\right)$ & $26.3 \pm 3.7$ & $26.0 \pm 3.6$ & $26.8 \pm 4.1$ & $28.1 \pm 3.7$ & $<0.001^{\mathrm{a}, \mathrm{b}, \mathrm{c}}$ \\
\hline Total cholesterol (mmol/l) & $6.6 \pm 1.2$ & $6.6 \pm 1.2$ & $6.5 \pm 1.2$ & $6.6 \pm 1.2$ & NS \\
\hline Triacylglycerol (mmol/l) & $1.53 \pm 0.01$ & $1.47 \pm 0.01$ & $1.83 \pm 0.07$ & $1.89 \pm 0.05$ & $<0.001^{\mathrm{a}, \mathrm{c}}$ \\
\hline HDL-cholesterol (mmol/l) & $1.34 \pm 0.37$ & $1.37 \pm 0.37$ & $1.25 \pm 0.37$ & $1.25 \pm 0.34$ & $<0.001^{\mathrm{b}, \mathrm{c}}$ \\
\hline Age at diagnosis (years) & NA & NA & $68.6 \pm 0.50$ & $74.8 \pm 0.34$ & $<0.001^{\mathrm{b}}$ \\
\hline
\end{tabular}

Values are means \pm standard errors unless otherwise indicated

${ }^{\mathrm{a}}$ For comparison between prevalent cases and participants without diabetes; ${ }^{\mathrm{b}}$ for comparison between incident cases and prevalent cases; ${ }^{\mathrm{c}}$ for comparison between incident cases and participants without diabetes

NA, not applicable

participants, the $-482 \mathrm{~T}$ allele was associated with increased risk of diabetes $(-482 \mathrm{CT}$ OR $1.47,-482 \mathrm{TT}$ OR $1.40, p=$ 0.009 for trend). Similar results were found in prospective analyses (-482CT HR 1.35 [95\% CI 0.96-1.89], -482TT HR 1.68 [95\% CI $0.91-3.1] ; p=0.03$ for trend). The $-455 \mathrm{~T}>\mathrm{C}$ polymorphism showed similar associations in lean participants.

In overweight participants, no significant effects of the $-482 \mathrm{C}>\mathrm{T}$ polymorphism on diabetes risk was observed, while carriers of the $-455 \mathrm{C}$ allele had lower prospective risk of type 2 diabetes (-455TC HR 0.88 [95\% CI 0.71-1.1], -455 CC HR 0.70 [95\% CI 0.49-0.998], $p=0.04$ for trend).

Replication and meta-analysis Baseline characteristics of the RSPlus1/DiaGene cohort are shown in Table 3. Cases were older $(p<0.001)$, had higher BMI $(p<0.001)$ and were more often men $(p<0.001)$ than controls. In the replication analyses, we found similar results to the original cohort, in

Table 2 HRs and ORs for incident and prevalent type 2 diabetes, replication and meta-analysis for APOC 3 genotypes in lean and overweight participants

\begin{tabular}{|c|c|c|c|c|c|c|c|c|c|c|c|}
\hline \multicolumn{2}{|l|}{ Variants } & \multicolumn{3}{|l|}{ RS1 HR } & \multicolumn{3}{|l|}{ RS1 OR } & \multicolumn{3}{|c|}{ Replication cohort } & \multirow{2}{*}{$\begin{array}{l}\text { Overall } \\
p \text { value }^{\mathrm{c}}\end{array}$} \\
\hline $\begin{array}{l}\text { Polymorphisms } \\
\text { per BMI }\end{array}$ & Genotype & $\begin{array}{l}\text { Incident } \\
\text { diabetes }^{\mathrm{a}}\end{array}$ & $95 \% \mathrm{CI}$ & $p$ trend & $\begin{array}{l}\text { Prevalent } \\
\text { diabetes }^{\mathrm{a}}\end{array}$ & $95 \% \mathrm{CI}$ & $p$ trend & $\mathrm{OR}^{\mathrm{b}}$ & $95 \%$ CI & $p$ trend & \\
\hline \multicolumn{12}{|l|}{$\mathrm{BMI} \leq 26 \mathrm{~kg} / \mathrm{m}^{2}$} \\
\hline \multirow[t]{3}{*}{$-482 \mathrm{C}>\mathrm{T}$} & $\mathrm{CC}$ & 1.0 & & & 1.0 & & & 1.0 & & & \\
\hline & $\mathrm{CT}$ & 1.35 & $(0.96-1.89)$ & & 1.47 & $(1.13-1.92)$ & & 1.06 & $(0.81-1.38)$ & & \\
\hline & $\mathrm{TT}$ & 1.68 & $(0.91-3.1)$ & 0.03 & 1.40 & $(0.83-2.35)$ & 0.009 & 1.99 & $(1.25-3.16)$ & 0.03 & $1.1 \times 10^{-4}$ \\
\hline \multirow[t]{3}{*}{$-455 \mathrm{~T}>\mathrm{C}$} & $\mathrm{TT}$ & 1.0 & & & 1.0 & & & 1.0 & & & \\
\hline & $\mathrm{TC}$ & 1.27 & $(0.89-1.8)$ & & 1.65 & $(1.24-2.20)$ & & 0.86 & $(0.66-1.13)$ & & \\
\hline & $\mathrm{CC}$ & 1.39 & $(0.85-2.28)$ & 0.1 & 1.40 & $(0.92-2.13)$ & 0.01 & 1.09 & $(0.74-1.62)$ & 0.9 & 0.04 \\
\hline \multicolumn{12}{|l|}{$\mathrm{BMI}>26 \mathrm{~kg} / \mathrm{m}^{2}$} \\
\hline \multirow[t]{3}{*}{$-482 \mathrm{C}>\mathrm{T}$} & $\mathrm{CC}$ & 1.0 & & & 1.0 & & & 1.0 & & & \\
\hline & $\mathrm{CT}$ & 1.04 & $(0.84-1.28)$ & & 0.85 & $(0.66-1.10)$ & & 1.04 & $(0.88-1.23)$ & & \\
\hline & $\mathrm{TT}$ & 0.56 & $(0.32-0.98)$ & 0.3 & 0.84 & $(0.51-1.39)$ & 0.22 & 1.47 & (1.08-1.99) & 0.05 & 0.73 \\
\hline \multirow[t]{3}{*}{$-455 \mathrm{~T}>\mathrm{C}$} & TT & 1.0 & & & 1.0 & & & 1.0 & & & \\
\hline & $\mathrm{TC}$ & 0.88 & $(0.71-1.1)$ & & 0.98 & $(0.76-1.25)$ & & 0.90 & $(0.76-1.06)$ & & \\
\hline & $\mathrm{CC}$ & 0.70 & $(0.49-0.998)$ & 0.04 & 0.71 & $(0.48-1.06)$ & 0.16 & 0.79 & $(0.62-1.02)$ & 0.05 & 0.003 \\
\hline
\end{tabular}

${ }^{\mathrm{a}}$ Adjusted for year of birth and sex

${ }^{\mathrm{b}}$ Adjusted for age and sex

${ }^{\mathrm{c}}$ Meta-analyses $p$ value combining RS1 and RSPlus1/DiaGene 
Table 3 Baseline characteristics from the RSPlus1/DiaGene sample

Unless otherwise shown, values are means \pm standard error

${ }^{a}$ Diabetes status missing for 25 participants

\begin{tabular}{lllll}
\hline Characteristics & All participants & \\
& a & Controls & Cases & $p$ value \\
$n$ & 4,134 & 2,292 & 1,817 & \\
Age (years) & $65.5 \pm 9.0$ & $64.4 \pm 7.8$ & $66.8 \pm 10.1$ & $<0.001$ \\
Men $(\%)$ & 48.4 & 44.3 & 53.7 & $<0.001$ \\
BMI $\left(\mathrm{kg} / \mathrm{m}^{2}\right)$ & $28.4 \pm 4.9$ & $26.9 \pm 3.9$ & $30.4 \pm 5.3$ & $<0.001$ \\
\hline
\end{tabular}

which the $-482 \mathrm{~T}$ allele increased type 2 diabetes risk in lean persons $(-482 \mathrm{CT} 1.06$ [95\% CI 0.81-1.38], -482TT 1.99 [95\% CI $1.25-3.16] ; p=0.03$ for trend). No significant effects were found for the $-482 \mathrm{C}>\mathrm{T}$ and $-455 \mathrm{~T}>\mathrm{C}$ polymorphisms in overweight participants $(p=0.05$ for trend for both).

In meta-analyses, the effect of the $-482 \mathrm{~T}$ allele in lean participants was confirmed ( $p=1.1 \times 10^{-4}$ in meta analysis). In overweight participants, a protective effect of the $-455 \mathrm{C}$ allele seemed to be present $(p=0.003)$

Insulin treatment in lean and overweight participants Table 4 shows the ORs for insulin treatment among participants with diabetes, according to the $-482 \mathrm{C}>\mathrm{T}$ and $-455 \mathrm{~T}>\mathrm{C}$ genotypes. None of the ORs was statistically significant in this small group of participants. However, there was a borderline significant interaction of the $-482 \mathrm{C}>\mathrm{T}$ polymorphism with BMI in participants with diabetes $(-482 \mathrm{C}>\mathrm{T} * \mathrm{BMI}, p=0.06)$ and a significant interaction for the $-455 \mathrm{~T}>\mathrm{C}$ polymorphism $(-455 \mathrm{~T}>\mathrm{C} * \mathrm{BMI}, p=0.02)$.

Intermediate traits The genotypes were not associated with BMI $(-482 \mathrm{C}>\mathrm{T}, p=0.60 ;-455 \mathrm{~T}>\mathrm{C}, p=0.21)$ or fasting triacylglycerol levels $(-482 \mathrm{C}>\mathrm{T}, p=0.67 ;-455 \mathrm{~T}>\mathrm{C}$, $p=0.73$ ). They were also not associated with fasting triacylglycerol levels within the high and low BMI groups (data not shown).

\section{Discussion}

Main findings In this population-based study, we found significant interactions between BMI and genetic variants in the $A P O C 3$ promoter for type 2 diabetes risk. Lean participants carrying the $-482 \mathrm{~T}$ allele had higher risk of type 2 diabetes. These results were replicated in an independent population. Moreover, $A P O C 3$ promoter variants showed a borderline significant interaction with BMI for the need for insulin therapy. Presence of the minor alleles showed a trend towards increased need for insulin therapy in lean participants. Conversely, in overweight participants the $-455 \mathrm{C}$ allele seemed protective against type 2 diabetes.

The RS1 study design included meticulous follow-up on disease outcomes over a long time. The large number of diabetic cases enabled us to replicate the findings within our population in prevalent and incident cases. Moreover, we were able to replicate and meta-analyse the findings by means of an independent population. Information on insulin treatment provided an important intermediate phenotype for the interpretation of our findings and the understanding of pathophysiological mechanisms. To our knowledge, this is the first study that shows an interaction between $A P O C 3$ variants and $\mathrm{BMI}$ to have an effect on type 2 diabetes risk.

Our results show that the effect of variation in the $A P O C 3$ gene is context-dependent. Our findings are not in
Table 4 Odds ratios for insulin treatment in lean and overweight participants with diabetes in RS1

\begin{tabular}{|c|c|c|c|c|}
\hline Polymorphism per BMI & Genotype & $\mathrm{OR}^{\mathrm{a}}$ & $95 \% \mathrm{CI}$ & $p$ value for trend \\
\hline \multicolumn{5}{|l|}{$\mathrm{BMI} \leq 26 \mathrm{~kg} / \mathrm{m}^{2} \mathrm{~b}$} \\
\hline \multirow[t]{3}{*}{$-482 \mathrm{C}>\mathrm{T}$} & $\mathrm{CC}$ & Reference & & \\
\hline & CT & 1.49 & $(0.89-2.49)$ & \\
\hline & $\mathrm{TT}$ & 1.66 & $(0.68-4.00)$ & 0.11 \\
\hline \multirow[t]{3}{*}{$-455 \mathrm{~T}>\mathrm{C}$} & $\mathrm{TT}$ & Reference & & \\
\hline & $\mathrm{TC}$ & 1.71 & $(0.95-3.08)$ & \\
\hline & $\mathrm{CC}$ & 1.64 & $(0.74-3.62)$ & 0.13 \\
\hline \multicolumn{5}{|l|}{ BMI $>26 \mathrm{~kg} / \mathrm{m}^{2 \mathrm{c}}$} \\
\hline \multirow[t]{3}{*}{$-482 \mathrm{C}>\mathrm{T}$} & $\mathrm{CC}$ & Reference & & \\
\hline & CT & 0.94 & $(0.63-1.41)$ & \\
\hline & TT & 1.26 & $(0.53-3.03)$ & 0.92 \\
\hline \multirow[t]{3}{*}{$-455 \mathrm{~T}>\mathrm{C}$} & $\mathrm{TT}$ & Reference & & \\
\hline & $\mathrm{TC}$ & 0.83 & $(0.56-1.25)$ & \\
\hline & $\mathrm{CC}$ & 0.78 & $(0.40-1.55)$ & 0.34 \\
\hline
\end{tabular}


line with the thrifty genotype hypothesis [27] or with the Barker hypothesis [28]. APOC3 variants were not associated with BMI. The common APOC3 variants have an intricate relationship with type 2 diabetes. We hypothesise that lean type 2 diabetes has a distinct molecular basis of its own or that it shares part of its aetiology with type 1 diabetes.

Previous studies Hokanson and colleagues found the APOC3 promoter variants to be associated with susceptibility to type 1 diabetes [14]. Our findings in the lean type 2 diabetes group are consistent with this finding, with ORs of similar magnitude and direction. Lean type 2 diabetes and type 1 diabetes may both have insulin deficiency as the main characteristic. A partly shared aetiology or at least genetic overlap in disease susceptibility may also explain the increased frequency of lean type 2 diabetes in families with type 1 diabetes and vice versa $[12,13]$. Patients with type 2 diabetes who have relatives with type 1 diabetes are leaner and have lower C-peptide concentrations than those with a family history of type 2 diabetes [29].

Our finding that lean carriers of the minor alleles may require insulin therapy more frequently points towards an effect of $A P O C 3$ variants on beta cell function. Nevertheless, the disease process could also involve insulin resistance. The EARS II study reported larger AUCs for glucose and insulin in carriers of the $-482 \mathrm{~T}$ allele after an OGTT [24]. The population of this study consisted of young, healthy, lean offspring of men with premature cardiovascular disease. It would follow therefore that $A P O C 3$ promoter variation increases insulin resistance at a young age, possibly resulting in type 2 diabetes and an earlier need for insulin therapy. Nevertheless, caution should be exercised when extrapolating differences in insulin and glucose AUCs in young healthy participants to relevance for diabetes risk at an older age. In a study of middle-aged participants, male homozygotes of the variant promoter alleles showed less increase in insulin levels after an OGTT [26]. This is in line with our findings in lean participants.

Pathophysiological hypotheses Strikingly, we found an opposite effect of $A P O C 3$ promoter variation in overweight participants, in whom it would seem to protect against type 2 diabetes. Possibly competing risks overruled the effect of the APOC3 polymorphism and even resulted in an inverse association in overweight participants. Alternatively, there could be a pathophysiological explanation based on the metabolic differences between lean and overweight patients. In lean participants, our findings could be explained as follows. The presence of the promoter polymorphisms results in insulin resistance at a molecular level; thus the insulin-resistant $A P O C 3$ promoter shows impaired insulin-mediated downregulation [19, 20]. Increased ApoC-III plasma levels have been described in type 2 diabetes, but were mostly interpreted as a consequence of the disease [30, 31]. A direct toxic effect of ApoC-III on beta cells was found in in vitro studies by Juntti-Berggren et al. [18]. Indirect mechanisms involving lipoprotein metabolism might play a role, too. However, we did not find an association of the promoter variation with fasting triacylglycerol levels. This, however, does not exclude an effect of the polymorphisms on NEFA flux. Defective inhibition of LPL by ApoC-III might raise levels of circulating NEFAs and thus affect insulin sensitivity and beta cell function [17, 32, 33].

In overweight participants, hyperinsulinaemia may partly restore the insulin-mediated downregulation and may prevent beta cell toxicity. Nonetheless we do not have a clear explanation for a protective effect. A number of studies have shown that LPL metabolism may differ between lean and obese participants. However, it is unknown how differences in lipoprotein composition [34] or post-translational regulation of LPL [35-37] influence susceptibility to type 2 diabetes. Taken together, APOC 3 promoter variation may directly affect beta cell function in lean participants and reduce type 2 diabetes risk in overweight participants by mechanisms that are at present unknown. Alternatively, it may affect type 2 diabetes risk in lean and obese individuals in opposing ways and by mechanisms that involve LPL function.

Study limitations Some limitations of our study need to be considered. Unfortunately, we could not compare our findings with currently published genome-wide association studies, since they were not publicly available for lean and overweight participants separately. We also cannot exclude the possibility that the observed effects are due to linkage disequilibrium with other variants in the $A P O C 3$ gene or other nearby genes in the APOA1-APOC3-APOA4-APOA5 cluster. Nonetheless, the localisation in an IRE, their defective insulin-mediated downregulation in vitro and the findings by Hokanson and colleagues in type 1 diabetes [14] make these polymorphisms likely candidates for type 2 diabetes susceptibility in lean participants. Another limitation of the study is the relatively small group of participants in which we found a borderline significant interaction for insulin use. Although these results can help focus hypotheses on the mechanism by which APOC3 polymorphisms affect type 2 diabetes risk, a type 1 error cannot be excluded. These results are merely an encouragement for further research replication in independent cohorts.

Conclusion Our findings indicate that $A P O C 3$ promoter variants significantly interact with BMI at a populationbased level, increasing type 2 diabetes risk in lean and 
possibly decreasing type 2 diabetes risk in overweight patients. The borderline interaction of the promoter variants with need for insulin treatment suggests beta cell function involvement in lean participants. Our results suggest a genetic overlap between type 1 and lean type 2 diabetes. A subset of type 2 diabetes has already been identified for patients with auto-antibodies, i.e. type 1.5 diabetes or Latent autoimmune diabetes of adulthood [38]. It would seem unlikely that ApoC-III is related to autoimmunity. Our findings may therefore relate to a different subgroup of lean diabetes patients that shows genetic overlap with type 1 diabetes.

Acknowledgements The Rotterdam Study is supported by: the Erasmus Medical Center and Erasmus University Rotterdam; the Netherlands Organization for Scientific Research; the Netherlands Organization for Health Research and Development (ZonMw); the Research Institute for Diseases in the Elderly; the Ministry of Education, Culture and Science; the Ministry of Health, Welfare and Sports; the European Commission; and the Municipality of Rotterdam. The molecular analyses of the present study were partly sponsored by Pfizer.

Duality of interest The authors declare that there is no duality of interest associated with this manuscript.

Open Access This article is distributed under the terms of the Creative Commons Attribution Noncommercial License which permits any noncommercial use, distribution, and reproduction in any medium, provided the original author(s) and source are credited.

\section{References}

1. Kahn CR (1994) Banting lecture. Insulin action, diabetogenes, and the cause of type II diabetes. Diabetes 43:1066-1084

2. Bray GA (1996) Health hazards of obesity. Endocrinol Metab Clin North Am 25:907-919

3. Seidell JC (1997) Time trends in obesity: an epidemiological perspective. Horm Metab Res 29:155-158

4. Garcia-Estevez DA, Araujo-Vilar D, Saavedra-Gonzalez A, Fiestras-Janeiro G, Cabezas-Cerrato J (2002) Glucose metabolism in lean patients with mild type 2 diabetes mellitus: evidence for insulin-sensitive and insulin-resistant variants. Metabolism 51:1047-1052

5. Van Haeften TW, Van Maarschalkerweerd WW, Gerich JE, Van der Veen EA (1991) Decreased insulin secretory capacity and normal pancreatic B-cell glucose sensitivity in non-obese patients with NIDDM. Eur J Clin Invest 21:168-174

6. Alvarsson M, Wajngot A, Cerasi E, Efendic S (2005) K-value and low insulin secretion in a non-obese white population: predicted glucose tolerance after 25 years. Diabetologia 48:2262-2268

7. Arner P, Pollare T, Lithell H (1991) Different aetiologies of type 2 (non-insulin-dependent) diabetes mellitus in obese and non-obese subjects. Diabetologia 34:483-487

8. Poulsen P, Levin K, Petersen I, Christensen K, Beck-Nielsen H, Vaag A (2005) Heritability of insulin secretion, peripheral and hepatic insulin action, and intracellular glucose partitioning in young and old Danish twins. Diabetes 54:275-283
9. Mills GW, Avery PJ, McCarthy MI et al (2004) Heritability estimates for beta cell function and features of the insulin resistance syndrome in UK families with an increased susceptibility to type 2 diabetes. Diabetologia 47:732-738

10. Lehtovirta M, Kaprio J, Forsblom C, Eriksson J, Tuomilehto J, Groop L (2000) Insulin sensitivity and insulin secretion in monozygotic and dizygotic twins. Diabetologia 43:285-293

11. Matsuda A, Kuzuya T (1994) Relationship between obesity and concordance rate for type 2 (non-insulin-dependent) diabetes mellitus among twins. Diabetes Res Clin Pract 26:137-143

12. Dahlquist G, Blom L, Tuvemo T, Nystrom L, Sandstrom A, Wall S (1989) The Swedish Childhood Diabetes Study-results from a nine year case register and a one year case-referent study indicating that type 1 (insulin-dependent) diabetes mellitus is associated with both type 2 (non-insulin-dependent) diabetes mellitus and autoimmune disorders. Diabetologia 32:2-6

13. Li H, Lindholm E, Almgren P et al (2001) Possible human leukocyte antigen-mediated genetic interaction between type 1 and type 2 diabetes. J Clin Endocrinol Metab 86:574-582

14. Hokanson JE, Kinney GL, Cheng S, Erlich HA, Kretowski A, Rewers M (2006) Susceptibility to type 1 diabetes is associated with ApoCIII gene haplotypes. Diabetes 55:834-838

15. Jong MC, Hofker MH, Havekes LM (1999) Role of ApoCs in lipoprotein metabolism: functional differences between ApoC1, ApoC2, and ApoC3. Arterioscler Thromb Vasc Biol 19:472-484

16. McGarry JD, Dobbins RL (1999) Fatty acids, lipotoxicity and insulin secretion. Diabetologia 42:128-138

17. Boden G (1997) Role of fatty acids in the pathogenesis of insulin resistance and NIDDM. Diabetes 46:3-10

18. Juntti-Berggren L, Refai E, Appelskog I et al (2004) Apolipoprotein CIII promotes $\mathrm{Ca}^{2+}$-dependent beta cell death in type 1 diabetes. Proc Natl Acad Sci U S A 101:10090-10094

19. Dammerman M, Sandkuijl LA, Halaas JL, Chung W, Breslow JL (1993) An apolipoprotein CIII haplotype protective against hypertriglyceridemia is specified by promoter and $3^{\prime}$ untranslated region polymorphisms. Proc Natl Acad Sci U S A 90:4562-4566

20. Li WW, Dammerman MM, Smith JD, Metzger S, Breslow JL, Leff T (1995) Common genetic variation in the promoter of the human apo CIII gene abolishes regulation by insulin and may contribute to hypertriglyceridemia. J Clin Invest 96:2601-2605

21. Hofman A, Breteler MM, van Duijn CM et al (2009) The Rotterdam study: 2010 objectives and design update. Eur J Epidemiol 24:553-572

22. Expert Committee on the Diagnosis and Classification of Diabetes Mellitus (1997) Report of the expert committee on the diagnosis and classification of diabetes mellitus. Diab Care 20:1183-1197

23. Alberti KG, Zimmet PZ (1998) Definition, diagnosis and classification of diabetes mellitus and its complications. Part 1: diagnosis and classification of diabetes mellitus provisional report of a WHO consultation. Diabet Med 15:539-553

24. Waterworth DM, Ribalta J, Nicaud V, Dallongeville J, Humphries SE, Talmud P (1999) ApoCIII gene variants modulate postprandial response to both glucose and fat tolerance tests. Circulation 99:1872-1877

25. Waterworth DM, Talmud PJ, Humphries SE et al (2001) Variable effects of the APOC3-482 $\mathrm{C}>\mathrm{T}$ variant on insulin, glucose and triglyceride concentrations in different ethnic groups. Diabetologia 44:245-248

26. Waterworth DM, Talmud PJ, Luan J et al (2003) Variants in the $A P O C 3$ promoter insulin responsive element modulate insulin secretion and lipids in middle-aged men. Biochim Biophys Acta 1637:200-206

27. Neel JV (1999) Diabetes mellitus: a "thrifty" genotype rendered detrimental by "progress"? 1962. Bull World Health Organ 77:694-703 
28. Barker DJ, Eriksson JG, Forsen T, Osmond C (2002) Fetal origins of adult disease: strength of effects and biological basis. Int $\mathbf{J}$ Epidemiol 31:1235-1239

29. Li H, Isomaa B, Taskinen MR, Groop L, Tuomi T (2000) Consequences of a family history of type 1 and type 2 diabetes on the phenotype of patients with type 2 diabetes. Diab Care 23:589594

30. Stalenhoef AF, Demacker PN, Lutterman JA, Van't Laar A (1982) Apolipoprotein C in type 2 (non-insulin-dependent) diabetic patients with hypertriglyceridaemia. Diabetologia 22:489-491

31. Florez H, Mendez A, Casanova-Romero P et al (2006) Increased apolipoprotein C-III levels associated with insulin resistance contribute to dyslipidemia in normoglycemic and diabetic subjects from a triethnic population. Atherosclerosis 188:134-141

32. Boden G, Jadali F, White J et al (1991) Effects of fat on insulinstimulated carbohydrate metabolism in normal men. J Clin Invest 88:960-966

33. Boden G (1996) Fatty acids and insulin resistance. Diab Care 19:394-395
34. Goldberg IJ, Vanni-Reyes T, Ramakrishnan S, Holleran S, Ginsberg HN (2000) Circulating lipoprotein profiles are modulated differently by lipoprotein lipase in obese humans. J Cardiovasc Risk 7:41-47

35. Ruge T, Sukonina V, Myrnas T, Lundgren M, Eriksson JW, Olivecrona G (2006) Lipoprotein lipase activity/mass ratio is higher in omental than in subcutaneous adipose tissue. Eur J Clin Invest 36:16-21

36. Pedersen SB, Jonler M, Richelsen B (1994) Characterization of regional and gender differences in glucocorticoid receptors and lipoprotein lipase activity in human adipose tissue. J Clin Endocrinol Metab 78:1354-1359

37. Fried SK, Russell CD, Grauso NL, Brolin RE (1993) Lipoprotein lipase regulation by insulin and glucocorticoid in subcutaneous and omental adipose tissues of obese women and men. J Clin Invest 92:2191-2198

38. Irvine WJ, McCallum CJ, Gray RS, Duncan LJ (1977) Clinical and pathogenic significance of pancreatic-islet-cell antibodies in diabetics treated with oral hypoglycaemic agents. Lancet 1:10251027 